\title{
HUBUNGAN KARAKTER DISIPLIN DENGAN KEMAMPUAN BERFIKIR SISWA DALAM KEGIATAN PEMBELAJARAN EKONOMI DI SMAN 2 SINGINGI
}

\author{
(The Relationship between Disciplinary Character and Students' Thinking ability in \\ Economic Learning Activities at SMAN 2 Singingi)
}

Oleh: Emilia Susanti, dan Almegi*)

E-mail: almegi@uin-suska.ac.id

*) Fakultas Tarbiyah dan Keguruan, UIN Sultan Syarif Kasim Riau

\begin{abstract}
This study aims to determine the relationship between the character of discipline and students 'thinking skills in economic learning activities at SMAN 2 Singingi which is motivated by the students' low ability to think in economic learning activities at SMAN 2 Singingi. This type of research is quantitative research. Subjects in the study of the relationship of character education with thinking skills of students in economic learning activities. Data collection techniques in this study used questionnaires, documentation and tests. The data analysis technique used is the correlation test using the Produck moment correlation formula. Based on the corelation test results obtained by Person Corelation value of 0.727 this means that there is a strong relationship between the character of discipline with students' thinking ability on economic subjects at SMAN 2 Singingi. this is also done by comparing $r$ Count with $r$ Table where (1\% 0.727>0.232), (5\% 0.727> 0.275). Then it can be concluded that Ha is accepted and $\mathrm{Ho}$ is rejected and from the results of the hypothesis test above it can be concluded that there is a significant relationship between the character of discipline and students' thinking ability on economic subjects at SMAN 2 Singingi.
\end{abstract}

Key words: disciplined characters, thinking ability, economic learning

\section{PENDAHULUAN}

Pendidikan karakter adalah suatu usaha pengembangan dan mendidik karakter seseorang, yaitu kejiwaan, akhlak, dan budi pekerti sehingga menjadi lebih baik. Pendidikan karakter adalah suatu sistem penanaman nilainilai karakter kepada warga sekolah yang meliputi komponen pengetahuan, kesadaran atau kemauan, dan tindakan untuk melaksanakan nilai-nilai tersebut. Pendidikan karakter dapat di maknai sebagai "the deliberate use all dimensions of school life to foster optimal character development".

Munculnya pendidikan karakter ini dilatarbelakangi oleh semakin merosotnya karakter anak bangsa di Indonesia, selain itu juga sebagai upaya membangun peserta didik yang berakhlak mulia. Menanamkan hal-hal baik pada pemahaman peserta didik akan menjadikan peserta didik lebih berakhlak mulia dalam kehidupan sehari-harinya. Maka dari itu, perlu dicetuskan pendidikan karakter bangsa sebagai wujud pendidikan karakter kebangsaan kepada peserta didik.

Karakter yang baik dapat diintegrasikan dalam kegiatan pembelajaran pada setiap mata pelajaran salah satunya pembelajaran ekonomi. Kegiatan pembelajaran dapat sejalan dengan penanaman norma dan nilai yang dapat di kaitkan dengan kehidupan sehari-hari. Pembelajaran karakter selain terdapat pada ranah kognitif juga menyentuh pada pengalaman nyata dalam kehidupan sehari-hari peserta didik. Hal ini menunjukkan pada 
pemfokusan penanaman karaker yang akan menjadikan peserta didik lebih disiplin dan sopan santun.

Munculnya karakter disiplin ini dilatar belakangi oleh semakin merosotnya karakter anak bangsa di Indonesia, selain itu juga sebagai upaya membangun peserta didik yang berakhlak mulia. Menanamkan hal-hal baik pada pemahaman peserta didik akan menjadikan peserta didik lebih berakhlak mulia dalam kehidupan sehari-hari mereka. Maka dari itu, perlu dicetuskan karakter disiplin bangsa sebagai wujud karakter disiplin kebangsaan kepada peserta didik.

Karakter yang baik dapat diintegrasikan dalam kegiatan pembelajaran pada setiap mata pelajaran salah satunya pembelajaran ekonomi. Kegiatan pembelajaran dapat sejalan dengan penanaman norma dan nilai yang dapat di kaitkan dengan kehidupan sehari-hari. Pembelajaran karakter selain terdapat pada ranah kognitif juga menyentuh pada pengalaman nyata dalam kehidupan sehari-hari peserta didik. Hal ini menunjukkan pada pemfokusan penanaman karaker yang akan menjadikan peserta didik lebih disiplin.

Disiplin dalam ruang lingkup sekolah dapat di bangun dan di kembangkan melalui aktivitas seperti mengikuti upacara bendera, berpakaian seragam, melakukan tugas kebersihan, mengumpulkan tugas tepat waktu, datang ke sekolah lebih awal dari jam pelajaran, mengerjakan tugas terstruktur walaupun tidak diperiksa atau belum sampai batas waktu yang ditentukan. Semua kegiatan ini dilakukan atas dasar kesadaran mendalam dan dorongan kuat yang lahir dari dalam (Yaumi, 2014).

Karakter yang benar-benar baik haruslah berpegang teguh pada sifat-sifat dan perbuatan-perbuatan baik yang telah ditetapkan Allah untuk kita dalam QS. Luqman (18-19) :

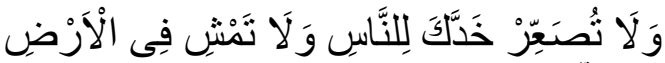

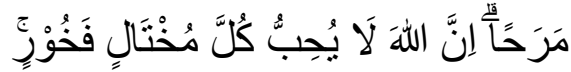 \\ "Dan janganlah kamu} memalingkan wajah dari manusia (karena sombong) dan janganlah kamu berjalan di bumi dengan angkuh. Sesungguhnya Allah tidak menyukai orang-orang yang sombong lagi membanggakan diri.",

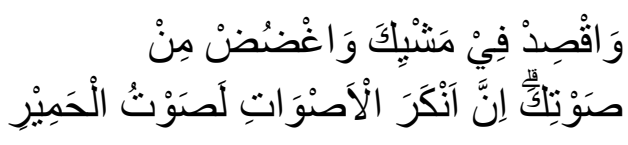

"Dan sederhanalah kamu dalam berjalan dan lunakkanlah suaramu. Sesungguhnya seburuk-buruk suara ialah suara keledai."

Tafsir ayat dalam buku Syaikh Abdurrahman bin Nashir as-Sa'di menafsirkan:

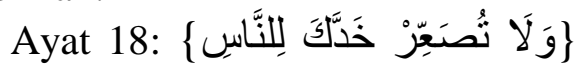

"Dan janganlah kamu memalingkan muka dari manusia" maksudnya jangan kamu memalingkannya dan jangan memasamkan mukamu kapada manusia karena sombong terhadap mereka dan

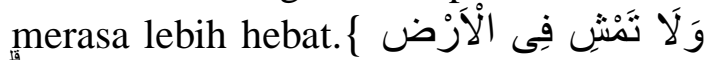

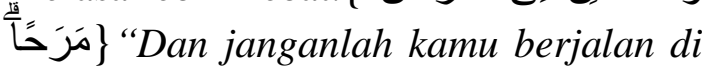
bumi dengan angkuh," dengan sombong, berbangga dengan berbagai nikmat, seraya melupakan Sang Maha Pemberi nikmat, dan bangga diri. "Sesungguhnya Allah tidak menyukai orang-orang yang sombong" dalam diri dan sikapnya dan

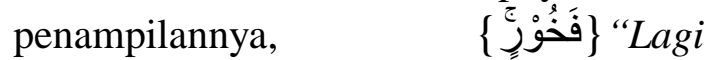
membanggakan diri. "dengan ucapannya (Abdurrahman, 2012).

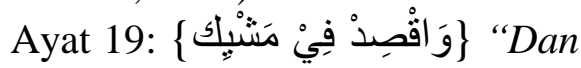
sederhanalah kamu dalam berjalan” Maksudnya, berjalanlah dengan tawadhu' (merendahkan diri) dan tenang, tidak dengan angkuh dan sombong, dan juga bukan jalan pura-pura mati,

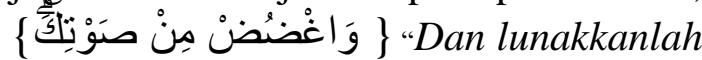
suaramu" sebagai etika terhadap orang 
lain dan terhadap Allah. \{ إنَّ آنْكَرَ

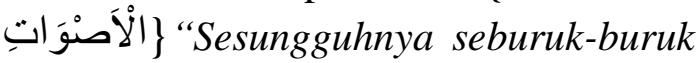
suara," yakni, yang paling keji dan

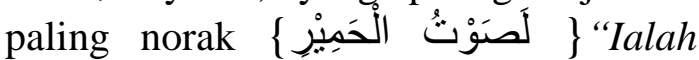
suara keledai." Kalau seandainya dalam meninggikan suara itu ada faidah dan maslahatnya, tentu Allah tidak mencontohkan dengan suara keledai yang telah di maklumi kekejian dan kedunguannya (Abdurrahman, 2012).

Surat Luqman ayat 18-19 memberi isyarat tentang pentingnya hati nurani. Yang dimaksud dengan hati nurani di sini adalah seseorang memiliki pengetahuan tentang apa yang baik (aspek kognitif), tetapi juga orang tersebut memiliki sisi emosi. Yang dimaksud dengan sisi emosi adalah perasaan wajib dan mendesak bahwa kebaikan tersebut segera dilaksanakan. Isyarat hati nurani pada ayat 18-19 adalah bahwa manusia dilarang berbuat sombong. Indikator orang sombong adalah memalingkan muka bila bertemu dengan orang lain, dan berjalan dengan angkuh. Selain itu Allah SWT meminta agar manusia berbicara dengan cara yang lunak. Ayat di atas, mengisyaratkan bahwa manusia harus memandang pentingnya tentang hati nurani. Pentingnya hati nurani bukan hanya dimiliki sebagai pengetahuan, tetapi hati nurani mendesak untuk dilaksanakan agar nilai-nilai kemanusiaan segera terwujud (Nugroho, 2014).

Kegiatan kognitif melibatkan lebih banyak pemfungsian pusat sistem syaraf (otak), oleh karenanya kegiatan semakin berdasarkan manipulasi representasi ide dari benda-benda dan situasi. Anderson dan Krathwohl mempertahankan kategori enam proses kognitif, yaitu: ingatan, memahami, menerapkan, menganalisis, mengevaluasi, dan menciptakan (Sunaryo, 2012). Peneliti tertarik untuk mengambil penelitian terkait mengingat/pengetahuan (C1) peserta didik.
Guru diharapkan tidak hanya memberikan pengetahuan sebanyakbanyaknya dalam kegiatan pembelajaran kepada peserta didik, tetapi juga mampu merangsang cara berfikir peserta didik, sehingga peserta didik mampu mengembangkan kebiasaan dan perilaku yang terpuji dan sejalan dengan nilainilai universal dan tradisi budaya bangsa yang religius.

Menurut hasil pengamatan di SMAN 2 Singingi penanaman pendidikan karakter terkait kedisiplinan sudah ditanamkan oleh guru pada diri peserta didik dengan baik namun kemampuan berfikir peserta didik pada mata pelajaran ekonomi masih rendah atau belum maksimal. Hal ini dapat di lihat dari gejala-gejala sebagai berikut:

1. Masih ada peserta didik yang tidak mampu menjawab pertanyaan yang di berikan oleh guru.

2. Masih ada peserta didik yang tidak dapat mengulang kembali jawaban yang diberikan temannya.

3. Masih ada peserta didik yang memperoleh nilai di bawah KKM.

Berdasarkan uraian di atas, maka perlu dilakukan penelitian untuk melihat hubungan karakter disiplin dengan kemampuan berpikir peserta didik dalam kegiatan pembelajaran Ekonomi di SMAN 2 Singingi.

\section{Karakter Disiplin}

Karakter menurut Kamus Besar Bahasa Indonesia merupakan sifat-sifat kejiwaan, akhlak atau budi pekerti yang membedakan seseorang dari yang lain. Dengan demikian karakter adalah nilainilai yang unik-baik yang terpateri dalam diri dan terjawantahkan dalam perilaku. Karakter secara koheren memancar dari hasil olah pikir, olah hati, olah rasa dan karsa, serta olahraga seseorang atau sekelompok orang (Hayati dan Nurhasnawati, 2014). 
Sikap disiplin adalah tindakan yang menunjukkan perilaku tertib dan patuh pada berbagai ketentuan dan peraturan. Dengan kepatuhan dan ketaatan terhadap aturan akan sangat memberikan manfaat dalam kehidupan seseorang yaitu kehidupan seseorang akan teratur, teratur dalam kegiatan sehari-hari, teratur dalam tugas dan tanggung jawab,teratur dalam kesehatan, kerapian dan kebersihan, dan teratur dalam beribadah (Hayati dan Nurhasnawati, 2014)

\section{Kemampuan Berpikir}

Kemampuan berfikir merupakan kemampuan memproses informasi secara mental atau secara kognitif. Secara lebih formal, berpikir adalah penyusunan ulang atau manipulasi kognitif baik informasi dari lingkungan maupun simbol-simbol yang disimpan dalam long term memory. Jadi, berpikir adalah sebuah representasi simbol dari beberapa peristiwa atau item (Andini, 2017).

Thinking skills is viewed as an intellectual or high-level cognitive process. Improving thinking has been the focus of education since the ancient Greeks. In Finland, there has been discussion about thinking skills in education, especially since 1980 (Aksela, 2005).

Maksudnya Kemampuan berpikir dipandang sebagai proses kognitif intelektual atau tingkat tinggi. Memperbaiki pemikiran telah menjadi fokus pendidikan sejak orang Yunani kuno. Di Finlandia, telah ada diskusi tentang kemampuan berpikir dalam pendidikan, terutama sejak tahun 1980.

Berfikir adalah daya yang paling utama dan merupakan ciri yang khas yang membedakan manusia dari hewan. Berfikir adalah suatu keaktipan pribadi manusia yang mengakibatkan penemuan yang terarah kepada suatu tujuan. Kita berfikir untuk menemukan pemahaman /pengertian yang kita kehendaki. Ciri-ciri utama dari berfikir adalah adanya abstraksi. Abstraksi dalam hal ini berarti: anggapan lepasnya kualitas atau relasi dari benda-benda, kejadiankejadian, dan situasi-situasi yang mulamula dianggap sebagai kenyataan (Ngalim, 2011).

\section{METODE PENELITIAN}

Metode penelitian yang digunakan adalah metode kuantitatif. Dalam penelitian kuantitatif dipergunakan data berupa angka dengan berbagai klarifikasi, antara lain berbentuk nilai rata-rata, persentase, nilai maksimum, dan lain-lain. Data tersebut merupakan bukti yang di pergunakan untuk menguji hipotesis dengan menunjukkan perbedaan, perbandingan, hubungan antara data yang satu dengan data yang lain (Mahmud, 2011).

Penelitian ini dilakukan pada bulan Desember 2019 s/d Maret 2020 dengan tempat pelaksanaan di SMAN 2 Singingi. Subjek dalam penelitian adalah guru dan peserta didik, sedangkan yang menjadi objek dalam penelitian adalah hubungan karakter disiplin dengan kemampuan berfikir peserta didik dalam kegiatan pembelajaran ekonomi.

Populasi dalam penelitian ini adalah seluruh peserta didik kelas $\mathrm{X}$ Jurusan IPS di SMAN 2 Singingi yang berjumlah 51 orang. Pengambilan sampel dilakukan dengan teknik sampel jenuh (saturated sampling), yaitu teknik penentuan sampel bila semua anggota populasi digunakan sebagai sampel. Teknik ini digunakan bila jumlah populasi relatif kecil, kurang dari 30 orang, atau penelitian yang ingin membuat generalisasi dengan kesalahan yang sangat kecil.

Data dalam penelitian ini dikumpulkan menggunakan angket, dokumentasi dan tes. Instrumen penelitian berupa angket dan tes terlebih dahulu dilakukan uji coba istrumen sebelum didistribusikan kepada 
responden dengan tahapan uji validitas instrumen dan uji reabilitas instrumen.

Metode Analisa data yang digunakan adalah analisis korelasi dengan prasaratnya yang mencakup; 1) Uji normalitas digunakan untuk mengetahui normal atau tidaknya sebaran data yang dianalisis, dan uji linearitas untuk mengetahui kelinearitasan data; 2) Analisis korelasi untuk mengetahui hubungan karakter disiplin ( $\mathrm{x}$ ) dengan kemampuan berfikir (y) menggunakan rumus pearson product moment; dan 3) Uji hipotesis digunakan untuk menemukan/mencari makna hubungan variabel bebas dengan variabel terikat. Hipotesis penelitian diujikan menggunakan uji t.

\section{HASIL}

Uji Normalitas dan Uji Linearitas

Uji normalitas sebaran data dengan metode Kolmogrov-Smirnov (taraf kepercayaan $95 \%$ atau $\alpha=0,05$ ) menggunakan hipotesis sebagai berikut:

Ho: data tidak berdistribusi normal jika nilai signifikansi $\leq 0,05$

H1: data berdistribusi normal jika nilai signifikansi $>0,05$

Tabel. 1 Hasil Uji Normalitas

One-Sample Kolmogorov-Smirnov Test

\begin{tabular}{|ll|c|}
\hline & & $\begin{array}{c}\text { Unstandardized } \\
\text { Residual }\end{array}$ \\
\hline $\mathrm{N}$ & & 51 \\
Normal Parameters ${ }^{\mathrm{a}, \mathrm{b}}$ & Mean & .0000000 \\
& Std. Deviation & 7.62111979 \\
Most Extreme Differences & Absolute & .102 \\
& Positive & .102 \\
& Negative & -.068 \\
Kolmogorov-Smirnov Z & & .726 \\
Asymp. Sig. (2-tailed) & & .668 \\
\hline
\end{tabular}

a. Test distribution is Normal. b. Calculated from data.

b. Calculated from data.

(Sumber: Data Olahan SPSS, 2020)

Tabel 2. Hasil Uji Linearitas

ANOVA Table

\begin{tabular}{|c|c|c|c|c|c|c|c|}
\hline & & & \begin{tabular}{|l|} 
Sum of \\
Squares
\end{tabular} & df & $\begin{array}{l}\text { Mean } \\
\text { Square }\end{array}$ & $\mathrm{F}$ & Sig. \\
\hline \multirow{5}{*}{$\begin{array}{l}\text { Kemampuan } \\
\text { Berfikir * } \\
\text { Karakter Disiplin }\end{array}$} & \multicolumn{2}{|c|}{ Between (Combined) } & 575.823 & 12 & 47.985 & .767 & .679 \\
\hline & Groups & Linearity & 47.966 & 1 & 47.966 & .767 & .387 \\
\hline & & $\begin{array}{l}\text { Deviation from } \\
\text { Linearity }\end{array}$ & 527.857 & 11 & 47.987 & .767 & .669 \\
\hline & \multicolumn{2}{|c|}{ Within Groups } & 2376.217 & 38 & 62.532 & & \\
\hline & \multicolumn{2}{|l|}{ Total } & 2952.039 & 50 & & & \\
\hline
\end{tabular}

(Sumber: Data Olahan SPSS, 2020) 
Hasil uji normalitas (Tabel 1), menunjukkan nilai signifikasi sebesar 0,668 . Artinya nilai signifikansi $0,668>$ 0,05 maka dapat dikatakan data berdistribusi normal dan layak untuk dianalisis lebih lanjut.

Uji linearitas menggunakan uji Anova (taraf kepercayaan 95\% atau $\alpha=$ $0,05)$, dengan hipotesis sebagai berikut:

Ho: distribusi data yang diteliti tidak mengikuti bentuk linear jika nilai signifikansi $\leq 0,05$

H1: distribusi data yang diteliti mengikuti bentuk linear jika nilai signifikansi $>0,05$

Hasil uji linearitas (Tabel 2), menunjukkan nilai signifikasi sebesar 0,669 . Artinya nilai signifikansi $0,668>$ 0,05 maka dapat dikatakan data mengikuti bentuk linear dan memiliki hubungan yang linear, sehingga layak untuk dianalisis lebih lanjut. b. Jika $t_{\text {hitung }}<t_{\text {tabel, }}$ maka $\mathrm{H}_{0}$ diterima dan $\mathrm{H}_{\mathrm{a}}$ ditolak, artinya tidak terdapat hubungan yang berarti.

\section{Analisis Korelasi}

Berdasarkan hasil uji korelasi menggunakan rumus pearson product moment untuk mengetahui hubungan Karakter Disiplin (X) terhadap Kemampuan Berfikir (Y), diperoleh nilai korelasi sebesar 0,727 dan signifikansi 0,00 . Hal ini menunjukkan bahwa terdapat hubungan yang kuat antara karakter disiplin dengan kemampuan berpikir siswa dalam kegiatan belajar ekonomi di SMAN 2 Singingi. Nilai yang positif menunjukkan arah hubungan yang positif, yaitu semakin tinggi kedisiplinan siswa maka kemampuan berpikir siswa juga semakin meningkat.

Tabel. 3 Hasil Analisis Korelasi Correlations

\begin{tabular}{|ll|c|c|}
\hline & & $\begin{array}{c}\text { Karakter- } \\
\text { Disiplin }\end{array}$ & $\begin{array}{c}\text { Kemampuan- } \\
\text { Berfikir }\end{array}$ \\
\hline Karakter- Disiplin & Pearson Correlation & 1 & .727 \\
& Sig. (2-tailed) & 51 & 000 \\
& $\mathrm{~N}$ & .727 & 51 \\
\hline Kemampuan-Berfikir & Pearson Correlation & 000 & 1 \\
& Sig. (2-tailed) & 51 & 51 \\
\hline
\end{tabular}

(Sumber: Data Olahan SPSS, 2020)

\section{Uji Hipotesis}

Uji hipotesis berfungsi mencari makna hubungan variabel bebas terhadap variabel terikat. Uji $\mathrm{t}$ digunakan untuk mengetahui tingkat signifikansi masingmasing variabel bebas terhadap variabel terikat.

a. Jika $t_{\text {hitung }} \geq t_{\text {tabel}}$, maka $\mathrm{H}_{0}$ ditolak dan $\mathrm{H}_{\mathrm{a}}$ diterima, artinya terdapat hubungan yang berarti antara penanaman karakter disiplin dengan kemampuan berfikir siswa. antara penanaman karakter disiplin dengan kemampuan berfikir siswa.

Hipotesis yang diuji adalah:

Ha: Adanya hubungan yang signifikan antara karakter disiplin dengan kemampuan berfikir siswa pada mata pelajaran Ekonomi di SMAN 2 Singingi.

Ho: Tidak adanya hubungan yang signifikan anatara karakter disiplin 
dengan kemampuan berfikir siswa pada mata pelajaran Ekonomi di SMAN 2 Singingi.

Selanjutnya nilai $r$ (hitung) yang diperoleh kemudian dikonsultasikan dengan nilai $\mathrm{r}$ (tabel) dengan terlebih dahulu mencari df yakni:

$\mathrm{Df}=51-2=49$

pada taraf signifikansi $1 \%=0,232$ pada taraf signifikansi $5 \%=0,275$.

Hasil analisis dari pengolahan data di atas menunjukan bahwa (1\% $0,727>0,232),(5 \% 0,727>0,275)$. Maka dapat disimpulkan bahwa $\mathrm{H}_{\mathrm{a}}$ diterima dan $\mathrm{H}_{\mathrm{o}}$ ditolak dan dari hasil uji hipotesis di atas disimpulkan terdapat hubungan yang signifikan antara karakter disiplin dengan kemampuan berfikir siswa pada mata pelajaran ekonomi di SMAN 2 Singingi.

\section{PEMBAHASAN}

$\begin{array}{ccc}\text { Berdasarkan } & \text { hasil analisis } \\ \text { korelasi diperoleh nilai pearson }\end{array}$ corelation sebesar 0,727 hal ini berarti terdapat hubungan yang kuat antara karakter disiplin dengan kemampuan berfikir siswa pada mata pelajaran ekonomi di SMAN 2 Singingi. Hasil ini selanjutnya juga dilakukan uji hipotesis dengan membandingkan $r$ Hitung dengan r Tabel dimana $(1 \% \quad 0,727>0,232),(5 \%$ $0,727>0,275)$. Maka dapat disimpulkan bahwa Ha diterima dan Ho ditolak dan dari hasil uji hipotesis di atas disimpulkan terdapat hubungan yang signifikan antara karakter disiplin dengan kemampuan berfikir siswa pada mata pelajaran ekonomi di SMAN 2 Singingi.

Hasil penelitian ini sesuai dengan apa yang disampaikan dalam sebuah teori, yaitu menurut Creasy dalam buku Zubaedi menyebutkan bahwa "hubungan pendidikan karakter tidak terbatas pada transfer pengetahuan mengenai nilainilai yang baik, namun lebih dari itu menjangkau pada bagaimana menjadikan nilai-nilai tersebut tertanam dan menyatu dalam totalitas pikiran-tindakan".

Pendidikan karakter memiliki tiga fungsi utama. Pertama, fungsi pembentukan dan pengembangan potensi. Pendidikan karakter berfungsi membentuk dan mengembangkan potensi peserta didik agar berpikir baik, berhati baik dan berperilaku baik sesuai dengan falsafah hidup pancasila. Kedua, fungsi perbaikan dan penguatan. Ketiga, fungsi penyaring.

Disiplin merupakan nilai karakter yang berhubungan dengan pola fikir dirinya sendiri agar dapat selalu menghargai waktu. Disiplin tidak hanya berkaitan dengan waktu, tetapi juga mengarah pada perilaku patuh terhadap aturan. Disiplin sebagai karakter yang menunjukkan perilaku tertib dan patuh pada beragai ketentuan dan peraturan.

Disiplin sebagai karakter yang melekat dalam diri manusia pada dasarnya dapat di jadikan sebagai kontrol diri. Disiplin adalah kontrol diri yang mendorong dan mengarahkan segala daya upaya untuk dapat menggapai sesuatu. Sebagai contoh, saat di rumah siswa akan belajar tanpa di suruh orang tuanya, hal ini dilakukan agar memperoleh nilai yang baik.

Disiplin dalam belajar akan dapat meningkatkan potensi dalam diri seseorang. Disiplin sebagai karakter dilakukan secara berkelanjutan, konsisten terhadap waktu dan hal yang di pelajari akan membawa seorang siswa dapat mewujudkan potensi. Hal ini dapat dilihat dari penulis atau musisi yang hebat terlahir bukan karena bakatnya saja, tetapi didukung juga dengan kedisiplinan belajar, sehingga segala potensi yang dimiliki dapat dikembangkan degan baik.

\section{KESIMPULAN}

Berdasarkan hasil uji korelasi diperoleh nilai person corelation sebesar 0,727 hal ini berarti terdapat hubungan 
yang kuat antara karakter disiplin dengan kemampuan berfikir siswa pada mata pelajaran ekonomi di SMAN 2 Singingi. Terhadap hasil ini juga dilakukan uji hipotesis dengan membandingkan $r$ Hitung dengan $\mathrm{r}$ Tabel dimana (1\% $0,727>0,232), \quad(5 \% \quad 0,727>0,275)$. Jika $\mathrm{t}_{\text {hitung }} \geq \mathrm{t}_{\text {tabel, }}$ Maka dapat disimpulkan bahwa Ha diterima dan Ho ditolak. Dari hasil uji hipotesis di atas disimpulkan bahwa terdapat hubungan yang signifikansi antara karakter disiplin dengan kemampuan berfikir siswa dalam kegiatan pelajaran Ekonomi di SMAN 2 Singigi.

\section{REFERENSI}

Abdurrahman, Syaikh Bin Nashir AsSa'di. 2012. Tafsir Al-qur'an. Jakarta Darul Haq.

Aksela, Maija. 2005. Supporting Meaningful Chemistry Learning and Higher-order Thinking through Computer-Assisted Inquiry: A Design Research Approach. Jurnal. Finland: University of Helsinki.

Andini, Kus Purbaningrum. 2017. Kemampuan Berfikir Tingkat Tinggi Siswa SMP Dalam Pemecahan Masalah Matematika Ditinjau Dari Gaya Belajar. Jurnal. Tangerang: Universitas Muhammadiyah Tangerang.

Hayati, Mardia \& Nurhasnawati. 2014. Desain Pembelajaran. Pekanbaru: Mutiara Pesisir Sumatra.

Mahmud. 2011. Metode Penelitian Pendidikan. Bandung: Pustaka Setia.

Mumpuni, Atikah. 2018. Integrasi Nilai Karakter dalam Buku Pelajaran: Analisis Konten Buku Pelajaran. Yogyakarta: Budi Utama.

Ngalim, M., Purwanto. 2011. Psikologi Pendidikan. Bandung: Remaja Rosdakarya.

Nugroho, Taufik. 2014. Pendidikan Karakter dalam Al-Qur'an (Studi Tafsir Pendidikan surat Luqman).
Jurnal. yogyakarta: Universitas Cokro Aminoto.

Sunaryo, Wowo Kuswana. 2012. Taksonomi Kognitif. Bandung: PT Remaja Rosdakarya.

Yaumi, Muhammad. 2014. Pendidikan Karakter: Landasan, Pilar dan Implementasi. Jakarta: Prenada media Group.

Zubaedi. 2011. Desain Pendidikan Karakter. Jakarta: Kencana. 